\title{
PERANCANGAN SISTEM INFORMASI ADMINISTRASI PADA PT.SCHOTERS BERBASIS JAVA
}

\author{
Muhammad Adriansyah Hasbad $^{1}$, Naely Farkhatin ${ }^{2}$, Surajiyo ${ }^{3}$ \\ ${ }^{1}$ Universitas Indraprasta PGRI, ${ }^{2}$ Universitas Indraprasta PGRI, ${ }^{3}$ Universitas Indraprasta PGRI \\ Jalan Nangka Raya No. 58 C, RT.5/RW.5, Tj.Barat, Jagakarsa, Kota Jakarta Selatan, DKI Jakarta 12530

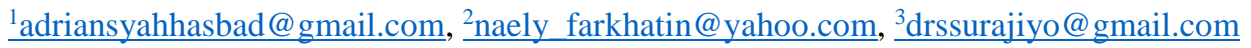

\begin{abstract}
ABSTRAK
Program komputer digunakan sebagai alat yang mempunyai kemampuan untuk membantu memecahkan masalah disegala aspek kehidupan. Misalnya di bidang pendidikan. Untuk mendapatkan ilmu pengetahuan kita bisa menempuh pendidikan formal. Dewasa ini banyak lembaga-lembaga baik pemerintah maupun swasta yang menawarkan program beasiswa. Sangat banyak program beasiswa yang disediakan mulai dari program pemerintah maupun swasta. Untuk mendapatkan beasiswa terkadang pemberi beasiswa mensyaratkan beberapa hal berkaitan dengan administrasi dan juga hal lainnya. PT.Schoters perusahaan yang bergerak dalam pelayanan penyediaan informasi, konsultasi, dan bimbingan untuk para pencari beasiswa agar mampu mendapatkan informasi terkait beasiswa yang dibutuhkan, konsultasi terkait beasiswa yang dibutuhkan mengenai jadwal penerimaan, syarat syarat yang dbutuhkan dan lain lain, dan juga bimbingan untuk para pencari beasiswa agar ketika mendaftarkan aplikasinya kesempatan untuk mereka diterima menjadi lebih besar. Tujuan diadakan penelitian ini agar PT.Schoters dapat memberikan layanan yang lebih baik dengan mengkomputerisasi sistem administrasi dalam perusahaannya. Adapun metode penelitian yang digunakan adalah dengan melakukan observasi dan wawancara dalam mendapatkan beberapa informasi. Dan dari hasil penelitian didapatkan bahwasannya PT.Schoters sudah sangat baik dalam mengelola sistem informasinya hanya saja masih belum terkomputerisasi.
\end{abstract}

Kata Kunci: Sistem Informasi, Sistem Administrasi, Java.

\section{ABSTRACT}

Computer programs are used as tools that have the ability to help solve problems in all aspects of life. For example in the field of education. To get knowledge, we can taking formal education. Today many institutions, both government and private, offer scholarship programs. There are many scholarship programs provided, starting from government and private programs. To get a scholarship sometimes the scholarship provider requires several things related to administration and also other things. PT.Schoters a company engaged in providing information, consultation, and guidance for scholarship seekers so that they are able to obtain information related to the scholarships needed, consultation regarding the scholarships needed regarding the schedule of admissions, the conditions needed and others, as well as guidance for students. scholarship seekers so that when registering their applications the chances of them being accepted are greater. The purpose of this research is so that PT.Schoters can provide better services by computerizing the administrative system within the company. The research method used is to make observations and interviews to get some information. And from the results of the study it was found that PT. Schoters was very good at managing its information system, it was just that it was not yet computerized.

Key word: System Information, Administration System,Java.

\section{PENDAHULUAN}

Perkembangan zaman kian pesat, membuat teknologi menjadi hal yang penting dalam kehidupan manusia. Teknologi menjadi penting karena mempermudah pekerjaan manusia. Komputer digunakan sebagai alat yang mempunyai kemampuan untuk membantu memecahkan masalah disegala aspek kehidupan salah satunya bidang pendidikan. Untuk mendapatkan ilmu pengetahuan bisa dimana saja, salah satunya dengan menempuh pendidikan formal.
Tentunya dalam menempuh pendidikan dibutuhkan biaya yang juga tidak sedikit. Oleh karena itu, dewasa ini banyak lembagalembaga baik pemerintah maupun swasta yang menawarkan program beasiswa.(Husada, 2019) Pada prinsipnya program beasiswa dibuat agar memfasilitasi teman teman yang mungkin memiliki minat yang kuat untuk belajar dan memiliki prestasi yang baik, baik dibidang akademik maupun non akademik namun mungkin mengalami masalah terkait biaya pendidikan yang 
lumayan mahal ataupun kendala lainnya.(Yusran, 2020) PT.Schoters melihat hal tersebut dan kemudian membuat sebuah unit usaha dalam membantu millennial yang punya semangat dalam menuntut ilmu. Penulis membuat penelitian ini agar membantu kelancaran sistem administrasi perusahaan agar lebih efektif dengan membuat sebuah konsep perancangan sistem. Suatu sistem adalah seperangkat elemen yang membentuk kumpulan atau prosedur-prosedur / bagan-bagan pengolahan yang mencari suatu tujuan tertentu.(Paryanta et al., 2017)

Sistem pada dasarnya adalah sekelompok unsur yang erat hubungannya antar yang satu dengan yang lainnya, yang berfungsi bersama -sama untuk mencapai tujuan tertentu.(Jeperson, 2015) Data yang telah diolah menjadi bentuk yang berarti bagi yang menerimanya dan bermanfaat dalam pengambilan keputusan saat ini dan saat mendatang (Nugraha \& Setiawan, 2016)

Perancangan Sistem informasi adalah gambaran suatu sistem yang dibuat secara umum berdasarkan seperangkat komputer dan komponen manual yang dapat dikumpulkan, disimpan dan diolah untuk menyediakan keluaran kepada pengguna.(saputra, 2019) Jadi, penulis membuat sebuah gambaran dalam sistem administrasi PT.Schoters.

\section{METODE PENELITIAN}

Metode yang digunakan oleh penulis dalam hal ini adalah metode kuantitatif, yakni metode sebagai upaya dalam menyelesaikan masalah, dimana dari masalah tersebut peneliti mengambil data, memetakan variable dan lalu diukur dengan angka-angka supaya dapat dilakukan analisa sesuai prosedur statistika yang telah berlaku. Adapun tujuannya supaya penulis bisa mengambil kesimpulan dalam penelitian ini.(Aldo \& Ardi, 2020).

\section{HASIL DAN PEMBAHASAN}

Diagram alir data merupakan suatu diagram yang menggambarkan aliran data dari sebuah proses atau sistem. DAD menyediakan informasi terkait keluaran dan masukan dari tiap entitas juga proses itu sendiri. DAD tidaklah mempunyai kendali atas alirannya. Tujuan dari DAD adalah menjadi penguhubung bagi pengguna juga pengembang sistem.(Simarmata, 2020)

\section{Diagram Konteks}

Diagram ini menerangkan tentang rancangan konsep bisnis yang saya usulkan kepada PT.Schoters dan alusr-alur dalam sistem informasi administrasi di PT.Schoters.(Purwati \& Hasan, 2016)

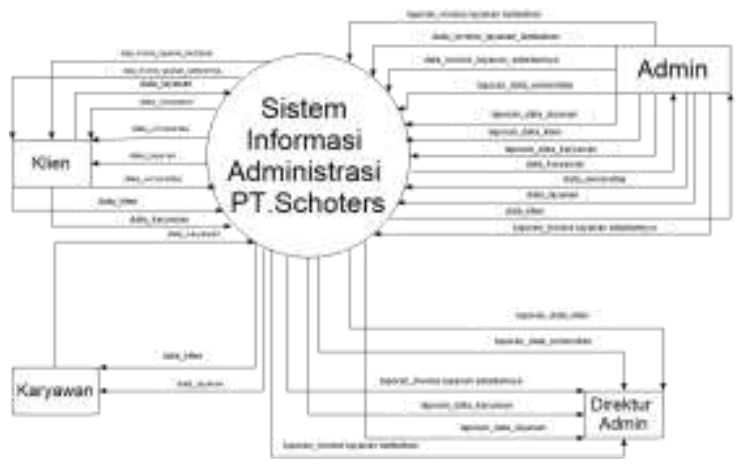

Gambar 1. Diagram Konteks

\section{Diagram Nol}

Diagram ini menjelaskan proses dan alur-alur pendataan dalam proses sistem informasi yang diusulkan pada PT.Schoters secara lebih detail dan mendalam.(Enterprise, 2015)

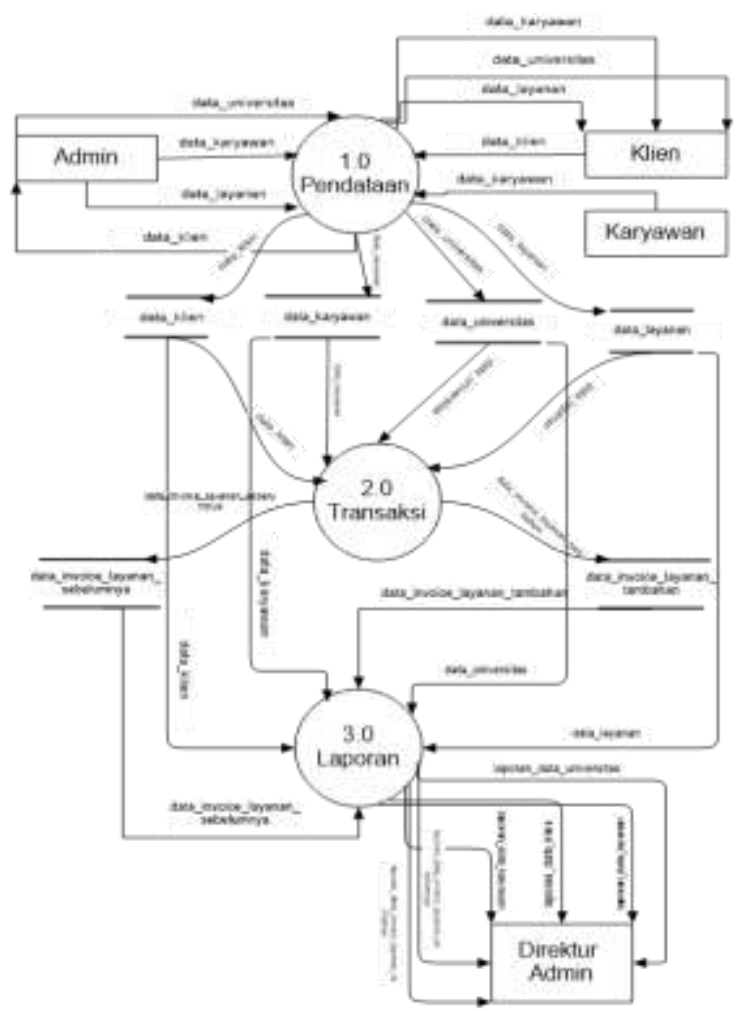

Gambar 2. Diagram Nol 


\section{Tampilan Layar Menu Utama}

Berikut tampilan layar awal ketika program dibuka pertama kali dan terdapat bebrapa menu yang dapat diklik.

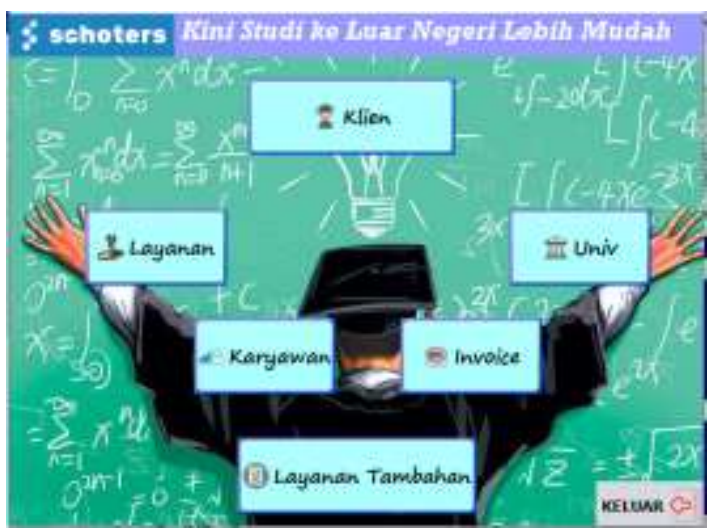

Gambar 3. Tampilan Layar Menu Utama

\section{Tampilan Layar Data Klien}

Berikut ini tampilan form untuk pengisian data klien PT.Schoters yang nantinya diinput oleh admin.

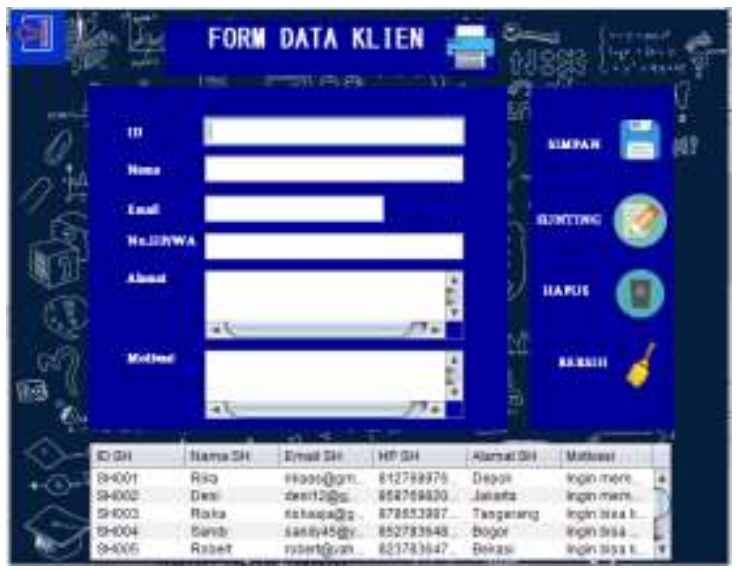

Gambar 4. Tampilan Layar Data Klien

\section{Tampilan Layar Data Layanan}

Berikut ini adalah tampilan form untuk pengisian data layanan PT.Schoters yang nantinya diinput oleh admin.

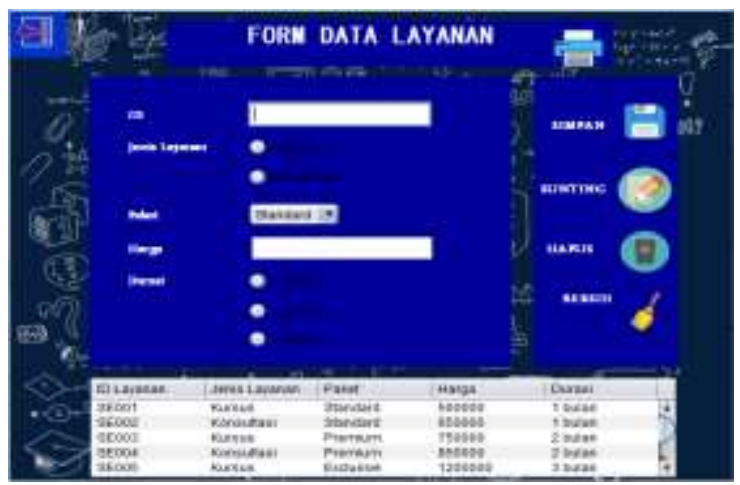

Gambar 5. Tampilan Layar Data Layanan
Tampilan Layar Data Karyawan

Berikut ini adalah tampilan form untuk pengisian data karyawan PT.Schoters yang nantinya diinput oleh admin.

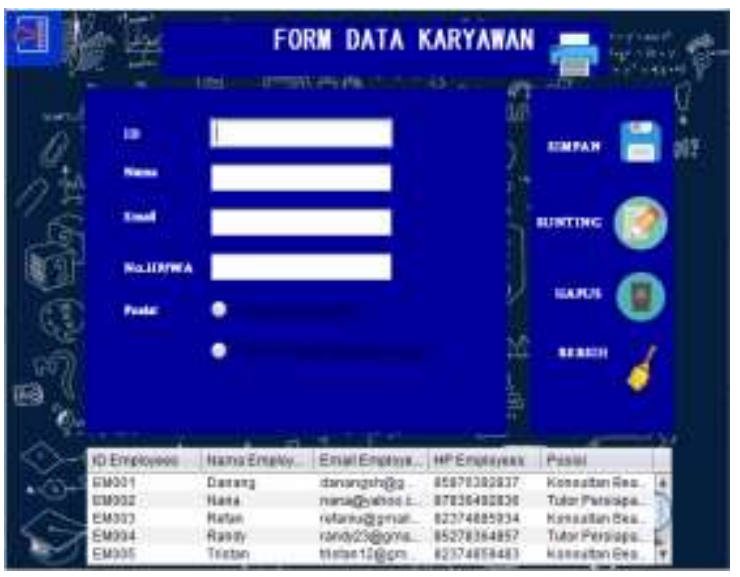

Gambar 6. Tampilan Layar Data Karyawan

Tampilan Layar Data Univ

Berikut ini adalah tampilan form untuk pengisian data universitas PT.Schoters yang nantinya diinput oleh admin.

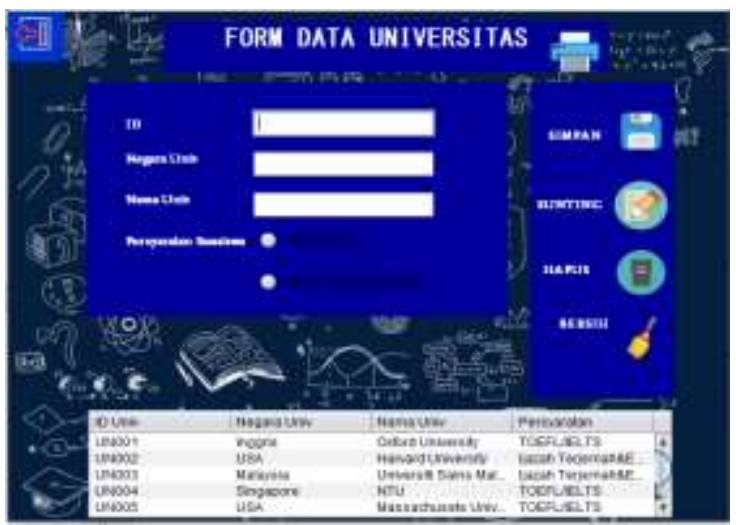

Gambar 7. Tampilan Layar Data Univ

\section{Tampilan Layar Data Invoice}

Berikut ini adalah tampilan form untuk pengisian data invoice PT.Schoters yang setiap nilainya diambil oleh form-form yang lain.

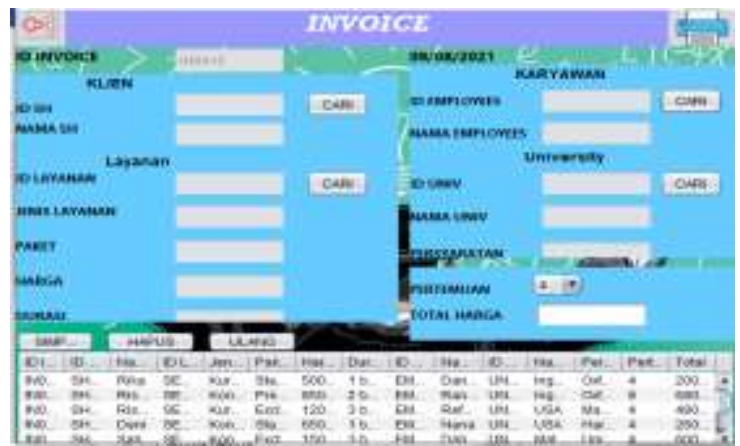

Gambar 8. Tampilan Layar Data Invoice

642 Perancangan Sistem Informasi Administrasi pada PT.Schoters Berbasis Java 


\section{Tampilan Output Invoice}

Berikut ini adalah tampilan output invoice yang muncul ketika admin selesai memasukkan data di invoice dan ketika admin mengklik tombol save.

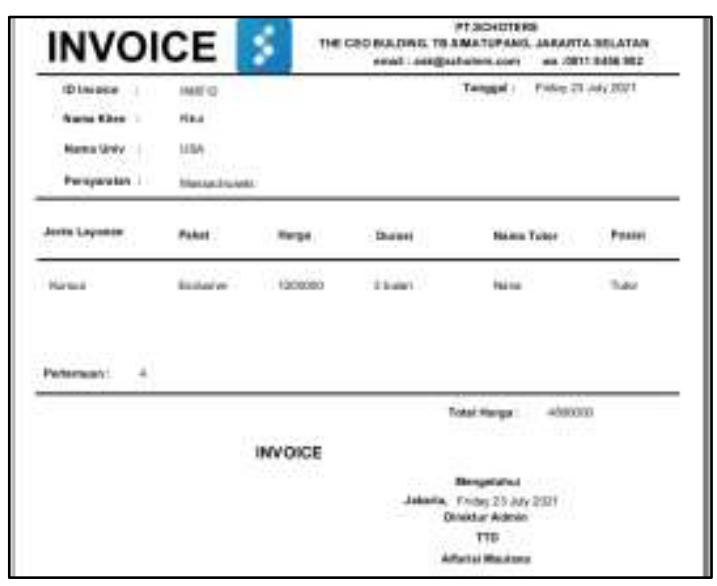

Gambar 9. Invoice

\section{Tampilan Output Lay.Tambahan}

Berikut ini adalah tampilan output layanan tambahan yang muncul ketika admin selesai memasukkan data di form layanan tambahan dan ketika admin mengklik tombol save.

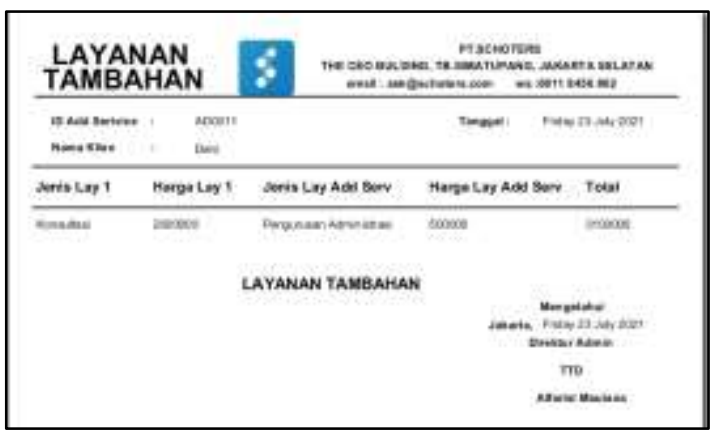

Gambar 10. Output Lay Tambahan

\section{SIMPULAN DAN SARAN}

Berdasarkan hasil penelitian penulis terhadap PT.Schoters Jakarta Selatan dapat disimpulkan bahwa aplikasi sistem admin yang telah penulis buat untuk PT.Schoters mampu mengurangi resiko kesalahan dalam penginputan dan pemrosesan data dikarenakan menggunakan sistem yang terintegrasi dan terkomputerisasi, juga dapat mengefesiensikan pengerjaan dalam pendataan informasi administrasi seperti pendataan data klien, data layanan, data universitas, data karyawan, pembuatan invoice, dan lain lain serta dengan adanya sistem informasi administrasi pada perusahaan dapat mempermudah admin dalam pembuatan laporan.

Dalam kesempatan ini penulis berharap dengan pembuatan sistem ini dapat membantu dan dapat dimanfaatkan sebaik baiknya untuk mempermudah pekerjaan admin dan atau karyawan di perusahaan.

\section{UCAPAN TERIMAKASIH}

Terima kasih sebesar besarnya penulis ucapkan terutama kepada Bapak Prof. Dr. H. Sumaryoto, Selaku Rektor Universitas Indraprasta PGRI. Bapak Radyum Ikono yang telah mengizinkan saya melakukan penelitian di perusahaan beliau. Serta semuanya yang tidak dapat penulis sebutkan satu per satu, yang telah membantu terselesaikannya artikel ini.

\section{DAFTAR PUSTAKA}

Aldo, D., \& Ardi. (2020). Pengantar Teknologi Informasi. CV.Insan Cendekia Mandiri. https://books.google.co.id/books?hl=en $\& \mathrm{lr}=\& \mathrm{id}=\mathrm{EE} 9 J \mathrm{DwAAQBAJ} \& \mathrm{oi}=\mathrm{fnd} \&$ $\mathrm{pg}=\mathrm{PP} 1 \& \mathrm{dq}=$ Enterprise,$+\mathrm{J} .+(2015) .+\mathrm{M}$ engenal+Java + Dan + Database + Dengan +Netbeans.+Jakarta:+Elex+Media+Ko

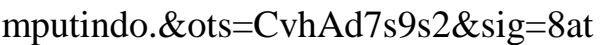
wwPDzHh5wJy1YtZ96ZcrAdYw\&redi $\mathrm{r} \_$esc $=\mathrm{y} \# \mathrm{v}=$ onepage $\& \mathrm{q} \& \mathrm{f}=$ false

Enterprise, J. (2015). Mengenal Java Dan Database Dengan Netbeans. Elex Media Komputindo.

Husada, F. R. K. (2019). No Title.E $\Lambda$ ENH. A $\alpha \propto \eta, 8(5), 55$.

Jeperson, H. (2015). Konsep Sistem Informasi. CV.Budi Utama.

Nugraha, S. A., \& Setiawan, R. (2016). Keuangan Sekolah Menengah Pertama Islam Terpadu. Jurnal STT-Garut All Right Reserved, 13(1), 320-332.

Paryanta, Sutariyani, \& Susilowati, D. (2017). Sistem informasi administrasi kependudukan berbasis web desa Sawahan. IJSE - Indonesian Journal on Software Engineering Sistem, 3(2), 7781.

Purwati, N., \& Hasan, N. (2016). Perancangan Sistem Informasi Administrasi Tamu Hotel (Studi Kasus Pada Hotel Ganesha Purworejo). Journal Speed - Sentra Penelitian Engineering Dan Edukasi, $8(1)$, 
ijns.org/journal/index.php/speed/article/ view/1395

saputra, R. (2019). Sistem Informasi Manajemen. CV.Insan Cendekia Mandiri. https://doi.org/10.31219/osf.io/v84sx

Simarmata, J. (2020). Teknologi Informasi:Aplikasi dan Penerapannya. Yayasan Kita Menulis.

Yusran, Y. (2020). Perancangan Sistem Informasi Administrasi Pembayaran SPP Siswa Berbasis Web. Edik Informatika, 6(2), 7-14. https://doi.org/10.22202/ei.2020.v6i2.3 980 